\title{
INTERNET OF THINGS AND BIG DATA ANALYTICS FOR HEALTH CARE WITH CLOUD COMPUTING
}

\author{
Dr. S. Smys, \\ Professor, Department of Computer Science and Engineering, \\ RVS Technical Campus, \\ Coimbatore, India. \\ Email: smys375@gmail.com \\ Dr. Jennifer S. Raj, \\ Professor, \\ Department of ECE, Gnanamani College of Technology, \\ Namakkal, India. \\ Email: jennifer.raj@gmail.com
}

\begin{abstract}
Nowadays the devices embedded with the internet connectivity termed as internet of things are constantly generating a monumental amount of the information. These huge set of data produced are coined as the big data. The big amount of data produced introduces complexity in analyzing and processing to extract the useful information's from them, this leads to the arising of the big data analytics that remains helpful in extracting the useful information from the huge set of data available. The paper also presents the internet of things and the big data analytics for monitoring the patients in the rural areas to have an improved planning, decision making and treatment with a reduced time and cost.
\end{abstract}

Keywords: Big Data Analytics, Health Care, Intelligent Development, Cloud Computing, Latency and Performance.

\section{INTRODUCTION}

The medical industry generates a huge amount of information's such as the impatient and out patient records, lab results, database management, medical imaging, patient examination, doctor consultation, patient monitoring etc. usually these data were stored in the hard copy form and were considered to be waste and were discarded after a certain period of time if the patient is not subjected to a regular visit. But nowadays all the information of the patient is digitized in order to acquire a valuable data's from the information recorded form the patients to enhance the quality of the medical services rendered as well as minimize the expense of the treatment. The author Raghupathi, in his paper says that "these huge volume of information's acquired from the medical industry were identified with promising and supporting suggestion's for a broader range of health care functions with the decision support, disease observation and population health management"[4]. 
Journal of Information Technology and Digital World (2019)

Vol.01/ No. 01

Pages: 9-18

https://www.irojournals.com/itdw/

DOI: https://doi.org/10.36548/jitdw.2019.1.002

The huge volume of data or the big data are the complex set of electronic information that is highly impossible to manage with the conventional hardware's or the soft wares and the data management tools and their algorithms. Especially in the field of heath care the big volume of data are overflowing and vast due to the diversities in the types of the information's that are gathered and the time required to process them. So altogether the information regarding the patients' health and the treatments provided for them makes the big-data for the medical industry [5].

The analytics techniques applied on the huge volume of data for analyzing the knowledge in it is called the big data analytics, the big data and the advanced analytics teamed up together enables to have most thoughtful developments in the today's business intelligence.

More over incorporating of the internet of things with the big data analytics enables to have a real time monitoring on the information gathered and allows making a perfect decisions in time to maintain the consistency and the throughput. In case of the health care it ensures the doctors with the real time monitoring of the patient health and allows him to make the perfect decision on the treatment to be provided in time. This will allow to reduce the latency in the treatment and as well as the cost of the treatment. The fig. 1 below shows big data analytics combined with the internet of things.

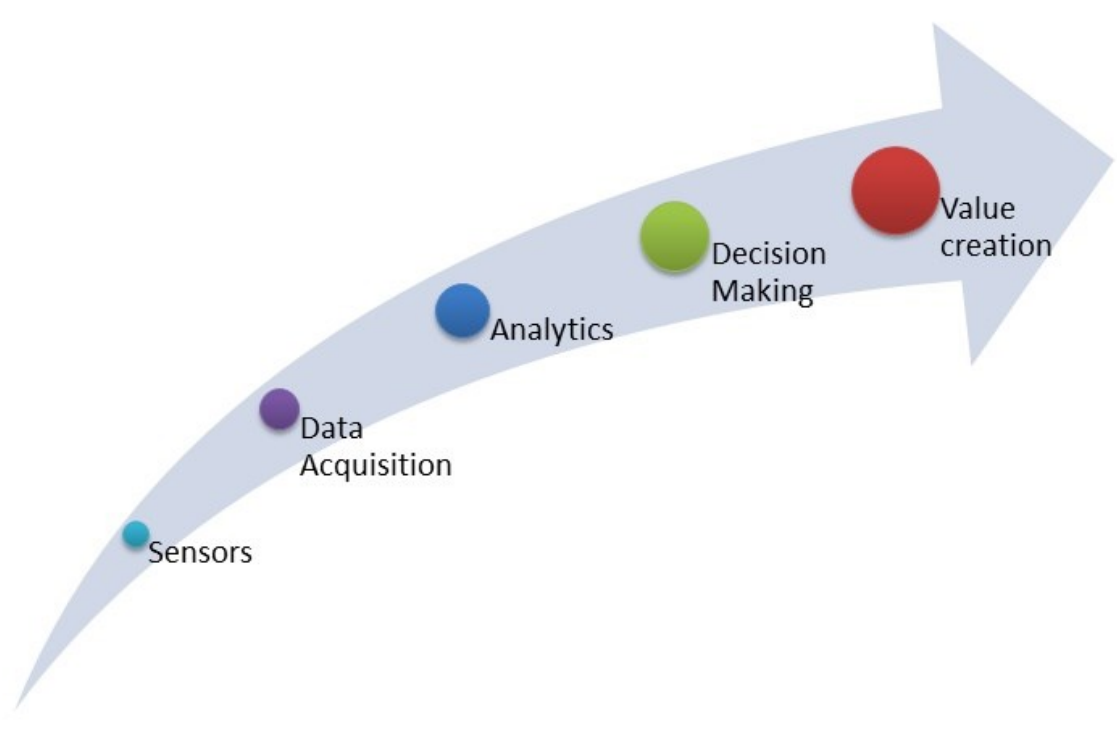

Fig .1 IOT with Big Data Analytics 
Journal of Information Technology and Digital World (2019)

Vol.01/ No. 01

Pages: 9-18

https://www.irojournals.com/itdw/

DOI: https://doi.org/10.36548/jitdw.2019.1.002

The development of the big data analytics combining internet of things with the cloud computing enhances the decision making and enables one to have a proper planning, organizing, leading, commanding and control [3]

The papers utilizes the internet of things and the big data analytics for health care with cloud computing for monitoring the sickly in the rural areas and provide them with the timely suggestions that could enable them to improve the health status.

The remaining of the paper is organized with the 2. Related works on the integration of the big data analytics and the internet of things in the health care, along with their potential and limitations. 3. Proposed work on the internet of things and the big data analytics for health care with cloud computing, 4. Results and discussion. 5. Conclusion

\section{RELATED WORKS}

Russom et al [1] the article is about the survey on the generation of the huge amount of data set from different fields and the "prevailing and he forth coming analytics that could be applied on the big set of data.Gandomi et al [2] the paper "documents the fundamental concepts related to the big-data and presents the overview of the constitutes of the big data, and the metrics that provide the volume and the attributes of the big data along with the technologies that are available to bind the potential of the big data.Sun et al [3] the author elaborates the intelligent big data analytics development and ensures that the intelligent big data analytics would cause a better planning, decision making, organizing, and controlling. Raghupathi, et al [4] the paper "describes the promises and the potential of the big data analytics but elaborating the benefits, the architectural frame work the methodology along with the challenges and the limitations in it Frost et al [5] the author brings out the significance of the big data in minimizing the complexities faced in the technology along with the cost reduction in the Gill, et al [6] the author in this paper describes the innovation of the big data in the health care. Sabharwal et al [7] the paper describes "the vital role of the big data analytics in enhancing the health conditions of the people to prevent them from major issues when used wisely. Manogaran et al [8]" the author details the novel architecture that integrates the big data and the internet of things for having a secured health care monitoring and the altering system" Sun et al [9] the paper describes the " concept of the smart and the connected communities by incorporating the big data analytics and the internet of things Thota et al [10], the author proffers a health care system by integrating the internet of things and the cloud computing and provides a centralized fog network for securing the services rendered. Dubey et al [11] Yassine et al [12],. Suma, V et al [13] the author in the paper proffers that the big data with the IOT would enable perfect decision 
Journal of Information Technology and Digital World (2019)

Vol.01/ No. 01

Pages: 9-18

https://www.irojournals.com/itdw/

DOI: https://doi.org/10.36548/jitdw.2019.1.002

making followed with the proper planning, organizing, leading, commanding and controlling avoiding the usage of the unwanted raw materials in the industries thus making the industry sustainable.

\section{PROPOSED WORK}

The paper proposes an internet of things combined with the big data for monitoring the patients in the rural areas. The rural areas are small villages with the limited accessibility for the physicians and the health centers. So this makes them to take a tiresome travel for the diagnosing of the disease or the treatment of the disease. This becomes even worse for the patients who are aged and unable to travel. So in order to avoid such situations and come up with the timely suggestion on the treatments for the disable persons and the sickly, the proposed method combines the IOT and the big data analytics along with the cloud computing.

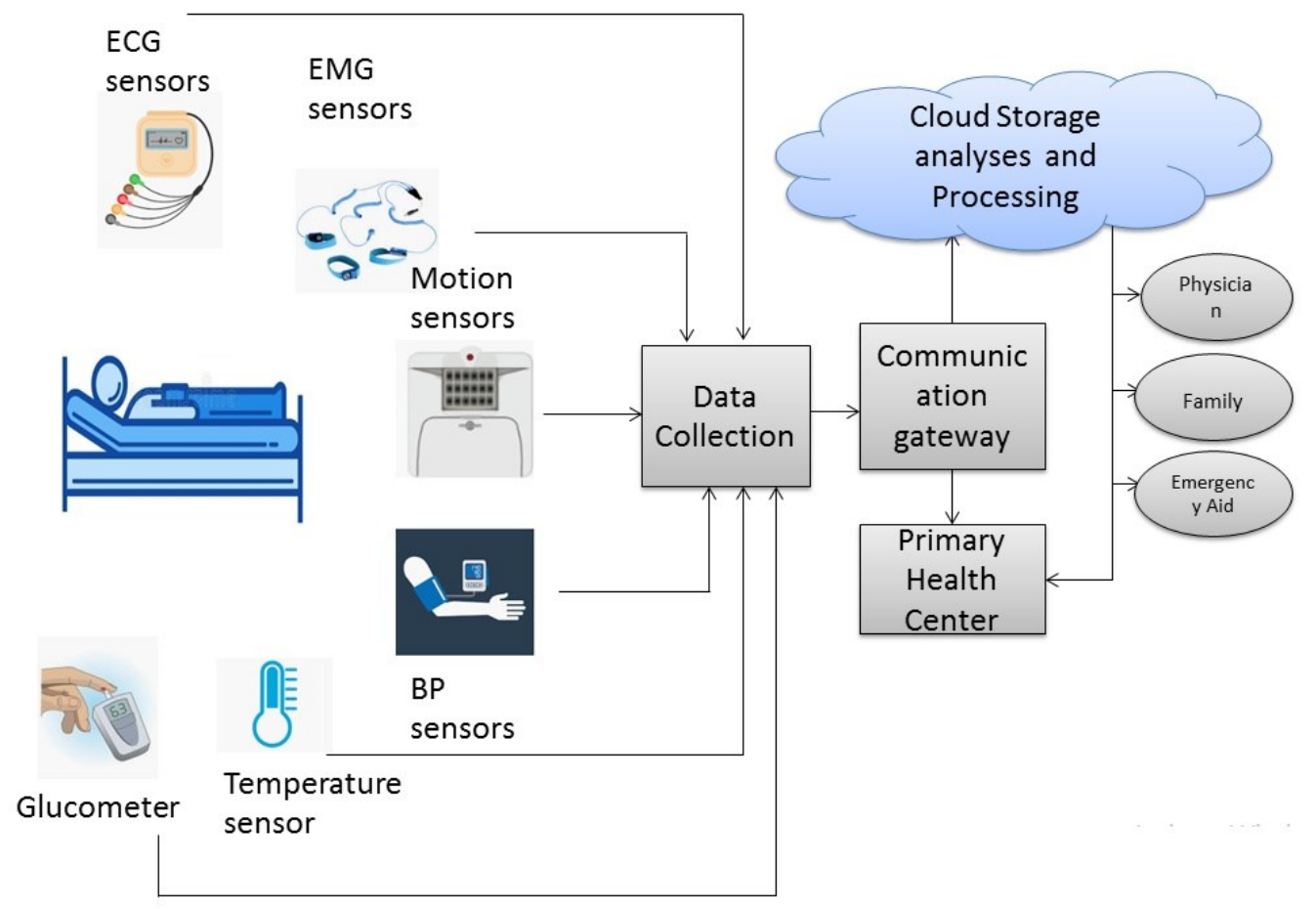

Fig.2 Proposed Frame Work 
Journal of Information Technology and Digital World (2019)

Vol.01/ No. 01

Pages: 9-18

https://www.irojournals.com/itdw/

DOI: https://doi.org/10.36548/jitdw.2019.1.002

The proposed method gathers the data of the patients using the separate sensors that are fixed on the patient's body for the monitoring of his ECG, heart rate, movement, blood pressure, temperature and the sugar level, these sensors used for the sensing the patients information's are enabled with the internet connectivity to transmit the data gathered to the smart phone or any other communication gateway that transfers the message sensed to the Cloud, the cloud performs the analytics on the huge set of data gathered from the patients using the Mahout [8] and extracts the insights present in the data gathered and conveys the information to the appropriate medical advisor, family as well as the medical aid in case of the emergency over the internet.

MAHOUT [8] is an apache project with the HDFS used in the processing and analyzing the valuable information from the data gathered. This Mahout is interconnected with S3 cloud storage solutions for the storing of the huge amount of $\log$ files in a distributed manner. A broader range of assistances can be provided in the healthcare industry using the big data by applying the analytical techniques to huge set of the patient health related problems. The analytical techniques applied to the patient's record based on the information gathered. The information gathered from the patient in the rural areas is analyzed immediately using the machine learning approach in the MAHOUT to know the seriousness in his /her body and the information is immediately transmitted to the nearby doctors in the primary heath as well as the physician who is in charge of the patient and the family member and the medical aid in times of the emergency, on the cases when the patient has to be shifted to the hospital. In case of less severity diagnosed from the patients regarding the disease, the doctor immediately responds back with the immediate suggestion on the first aid or the treatment that has to be provided causing a less weariness for the patients and the care taker. The table below shows the training data observed form the cardiology section in the hospital used in the MAHOUT APACHE. 
Journal of Information Technology and Digital World (2019)

Vol.01/ No. 01

Pages: 9-18

https://www.irojournals.com/itdw/

DOI: https://doi.org/10.36548/jitdw.2019.1.002

\begin{tabular}{|c|c|c|}
\hline Characteristics & Variation & Description \\
\hline AGE & Continuous & Age in years \\
\hline SEX & $0 / 1$ & 1-male, 0 -female \\
\hline Chest Pain & $1-4$ & $\begin{array}{l}\text { 1- Typical angina ,2- non angina } \\
\text { pain,3-atypical angina, 4- } \\
\text { asymptomatic }\end{array}$ \\
\hline Cholesterol & Continuous & In mg/dl \\
\hline ECG Results & $0-2$ & $\begin{array}{l}\text { 0-normal ,1-abnormal,2- showing } \\
\text { probable left ventricle hypertrophy }\end{array}$ \\
\hline Resting blood pressure & Continuous & mm High readmit hospital \\
\hline exercise induced angina & $0-1$ & 0 -no 1-yes \\
\hline fasting blood sugar & $0-1$ & 1 true, 0 -false $>$ than $120 \mathrm{mg} / \mathrm{dl}$ \\
\hline $\mathrm{CA}$ & $0-3$ & $\begin{array}{l}\text { Major vessels colored by } \\
\text { fluoroscopy }\end{array}$ \\
\hline Thal & $0-2$ & $\begin{array}{l}\text { 0-normal, 1-fixed defect, } 7 \text { - } \\
\text { reversible defect }\end{array}$ \\
\hline NUM & $0-1$ & $\begin{array}{l}\text { 0-healthy, 1- patient with the } \\
\text { probability of heart disease }\end{array}$ \\
\hline
\end{tabular}

Table .1 Training Data Used

The proposed model of the IOT integrated with the big data analytics utilizing the MAHOUT APACHE[8] enhances the observation associated with the health of the public and enables to have a speedy response from the concerned persons with the valuable suggestions or the advice, the medication to be taken, the identification of the essential equipment's that are required for monitoring the heath, delivering those services along with the prevention measures that reduce the fatalities in the rural areas.

The big data analytics based on the mahout also enables to have a suggestion based medication by integrating and analyzing the various structured and the unstructured medical records, the clinical data and the inheritable traits of the humans and matches the corresponding treatments with the results and provides the severity of the disease in the patient and put forward the recommendations to the readmitting of the patient or the more effective care to be taken. The real time analysis provided by the IOT integrated big data analytics ensure the patient safety as well as reduces 
Journal of Information Technology and Digital World (2019)

Vol.01/ No. 01

Pages: 9-18

https://www.irojournals.com/itdw/

DOI: https://doi.org/10.36548/jitdw.2019.1.002

the time and the cost spent on the diagnosis. The table. 2 below shows the threshold level set for the sensors in monitoring the patient $\mathrm{s}$ health to perform refining of the data using the Mapreduce

\begin{tabular}{|c|c|c|c|}
\hline \multirow{2}{*}{$\begin{array}{l}\text { Sensor } \\
\text { Measurement }\end{array}$} & \multirow[t]{2}{*}{ Verge level of the sensors } & \multicolumn{2}{|c|}{ Condition of the Patient } \\
\hline & & Serious & Not Serious \\
\hline \multirow[t]{3}{*}{ Temperature } & Less than $98.3 \mathrm{~F}-$ low & serious & \\
\hline & 98.3F-normal & & Not serious \\
\hline & More than 98.3F-high & Serious & \\
\hline \multirow[t]{3}{*}{ Blood Pressure } & $<60$-low & - & - \\
\hline & $60-140$-moderate & & Not serious \\
\hline & $>140$ high & Serious & \\
\hline \multirow[t]{3}{*}{ Heart Rate } & $<60$-low & - & - \\
\hline & $60-100$ moderate & & Not serious \\
\hline & $>100$-high & Serious & \\
\hline \multirow[t]{3}{*}{ Sugar Level } & $<70-$ low & - & - \\
\hline & 70-120-moderate & & Not serious \\
\hline & >120-high & Serious & \\
\hline \multirow[t]{3}{*}{ Movement } & $40 \%$ movement normal & & Not serious \\
\hline & $20 \%$ needs doctor advice & Serious & \\
\hline & $<20 \%$ needs readmission & Serious & \\
\hline
\end{tabular}

Table .2 Threshold Levels of Sensors

\section{RESULTS AND DISCUSSION}

The Mahout that refines the input data observed from the sensors using the MAPREDUCE applies the machine learning algorithms to analyze the information's gained from the patients; it is trained with the training data based on the age, sex, chest pain, sugar level, heart rate, input heart CSV and the output heart model, THAL, CA, NUM of the heart disease patients gathered from the cardiology section of the hospital and tested with the MAHOUT.org.apache, mahout.classifier.sgdRUNLogistics-accuracy-scores-confusion. 
Journal of Information Technology and Digital World (2019)

Vol.01/ No. 01

Pages: 9-18

https://www.irojournals.com/itdw/

DOI: https://doi.org/10.36548/jitdw.2019.1.002

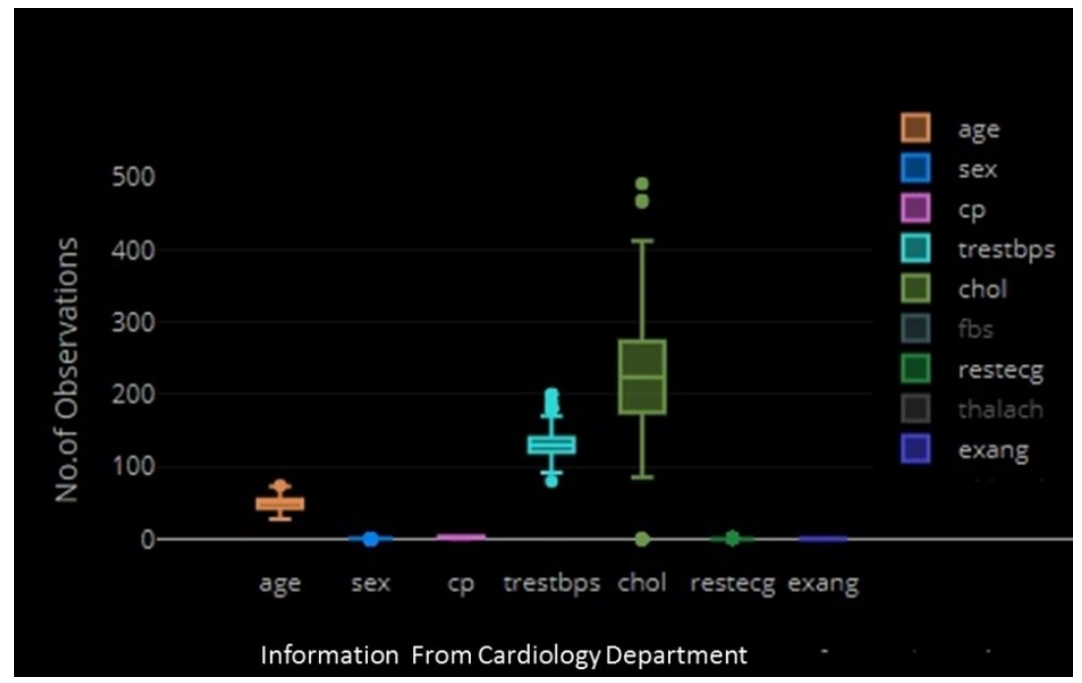

Fig .3. Information Gathered from the Cardiology Section

The fig.3above shows the number of the observations and the information gathered from the cardiology section of the hospital. Based on the 500 observations of the patient's record from a rural village, the predictability, and the accuracy is evaluated. Further the latency in the provision of the services and the performance of the IOT integrated big data analytics model is observed. The fig. 4 below shows the predictability and the accuracy percentage of the IOT integrated big data analytics in the health care monitoring and the service rendering of the patients in the rural areas.

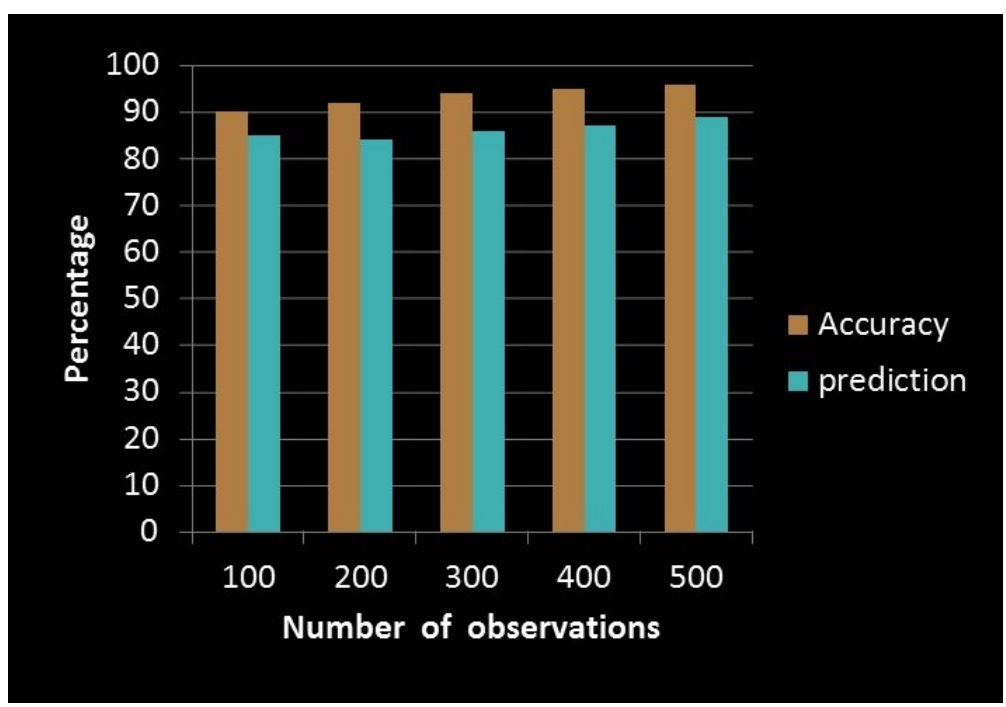

ISSN: 2582-418X (online) 
Journal of Information Technology and Digital World (2019)

Vol.01/ No. 01

Pages: 9-18

https://www.irojournals.com/itdw/

DOI: https://doi.org/10.36548/jitdw.2019.1.002

Fig .4 Percentage of Prediction and Accuracy

The table. 3 below gives the latency in the information gathering, transmitting and the analyzing and reporting back with the service form the physician for the different number of patients details sensed.

\begin{tabular}{|c|c|c|c|c|}
\hline $\begin{array}{l}\text { No. of } \\
\text { patients } \\
\text { records }\end{array}$ & $\begin{array}{c}\text { Latency in } \\
\text { information } \\
\text { gathering in ms }\end{array}$ & $\begin{array}{c}\text { Latency in } \\
\text { information } \\
\text { transfer in ms }\end{array}$ & $\begin{array}{c}\text { Latency in } \\
\text { the analyzing } \\
\text { in ms }\end{array}$ & $\begin{array}{c}\text { Latency in } \\
\text { Reporting } \\
\text { back in ms }\end{array}$ \\
\hline 100 & 0.0015 & 0.0089 & 0.0143 & 0.0127 \\
\hline 200 & 0.0027 & 0.0094 & 0.0252 & 0.0154 \\
\hline 300 & 0.0038 & 0.0095 & 0.0355 & 0.0175 \\
\hline 400 & 0.0045 & 0.0093 & 0.0357 & 0.0186 \\
\hline 500 & 0.0053 & 0.0091 & 0.0465 & 0.0194 \\
\hline
\end{tabular}

Table .3 Latency Observed

From the latency in the table observed, it is clear the IOT integrated with the big data analytics provides a timely treatment for the patients in the remote location.

\section{CONCLUSION}

The paper promoting the internet of things integrated with the big data analytics for the patients monitoring in the rural areas concentrates on the analyzing of the patients affected by the cardiac disease. It gathers the information using the sensors and transmits it over the internet to the cloud were the analytics is applied on the big data, the information are stored in the S3 cloud storage and analyzed using the MAHOUT provides the Mapreduce for the refining of the information gathered and machine learning algorithms for the analyzing of the information to diagnose the severity of the disease. The evaluation of the integrated IOT and big data analytics for patient monitoring in the rural areas based on the details recorded for 500 observations evinces the enhanced prediction and the accuracy in the heath monitoring and the reduced latency in the rendering of the service. In future in order to further reduce the latency the paper uses both the fog and the cloud network for the analyzing and storing respectively. 
Journal of Information Technology and Digital World (2019)

Vol.01/ No. 01

Pages: 9-18

https://www.irojournals.com/itdw/

DOI: https://doi.org/10.36548/jitdw.2019.1.002

\section{References}

[1] Russom, Philip. "Big data analytics." TDWI best practices report, fourth quarter 19, no. 4 (2011): 1-34.

[2] Sun, Zhaohao. "Intelligent Big Data Analytics: A Managerial Perspective." In Managerial Perspectives on Intelligent Big Data Analytics, pp. 1-19. IGI Global, 2019.

[3] Gandomi, Amir, and Murtaza Haider. "Beyond the hype: Big data concepts, methods, and analytics." International journal of information management 35, no. 2 (2015): 137-144.

[4] Raghupathi, Wullianallur, and Viju Raghupathi. "Big data analytics in healthcare: promise and potential." Health information science and systems 2, no. 1 (2014): 3.

[5] Frost, Sullivan. "Drowning in big data? reducing information technology complexities and costs for healthcare organizations." (2015).

[6] Gill, Jasmeen, M. Gobindgarh, S. Singh, and D. Baresary. "Big data: Big innovations in healthcare." Imperial Journal of Interdisciplinary Research (IJIR) 1, no. 6 (2015): 18.

[7] Sabharwal, Satwik, Samridhi Gupta, and K. Thirunavukkarasu. "Insight of big data analytics in healthcare industry." In 2016 International Conference on Computing, Communication and Automation (ICCCA), pp. 95-100. IEEE, 2016.

[8] Manogaran, Gunasekaran, Ramachandran Varatharajan, Daphne Lopez, Priyan Malarvizhi Kumar, Revathi Sundarasekar, and Chandu Thota. "A new architecture of Internet of Things and big data ecosystem for secured smart healthcare monitoring and alerting system." Future Generation Computer Systems 82 (2018): 375-387.

[9] Sun, Yunchuan, Houbing Song, Antonio J. Jara, and Rongfang Bie. "Internet of things and big data analytics for smart and connected communities." IEEE access 4 (2016): 766-773.

[10] Thota, Chandu, Revathi Sundarasekar, Gunasekaran Manogaran, R. Varatharajan, and M. K. Priyan. "Centralized fog computing security platform for IoT and cloud in healthcare system." In Fog Computing: Breakthroughs in Research and Practice, pp. 365-378. IGI global, 2018.

[11] Dubey, Harishchandra, Jing Yang, Nick Constant, Amir Mohammad Amiri, Qing Yang, and Kunal Makodiya. "Fog data: Enhancing telehealth big data through fog computing." In Proceedings of the ASE bigdata \& socialinformatics 2015, p. 14. ACM, 2015.

[12] Yassine, Abdulsalam, Shailendra Singh, M. Shamim Hossain, and Ghulam Muhammad. "IoT big data analytics for smart homes with fog and cloud computing." Future Generation Computer Systems 91 (2019): $563-573$.

[13] Suma, V. "TOWARDS SUSTAINABLE INDUSTRIALIZATION USING BIG DATA AND INTERNET OF THINGS." Journal of ISMAC 1, no. 01 (2019): 24-37.

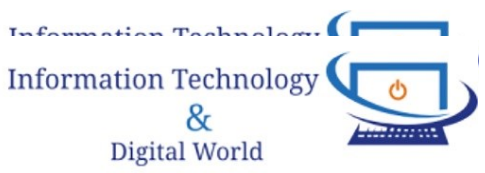

